\title{
Inter-linkages among socioeconomic deprivation, food insecurity, physical and psychosocial status in urban geriatric subjects: Varanasi, India
}

\author{
Priya Keshari* ${ }^{* 1}$ and Hari Shankar ${ }^{2}$ \\ ${ }^{\prime}$ Department of Home Science, Faculty of Science, University of Allahabad, India. \\ ${ }^{2}$ Department of Community Medicine, Institute of Medical Sciences, Banaras Hindu University, India.
}

\begin{abstract}
Geriatric subjects are vulnerable to Socio Economic Deprivation(SED), food and nutrition insecurity, poor nutritional status , morbidities, physical dependence, cognitive impairment and depression. Their inter-linkages is a least explored area of research. This aspect has been explored in this study by adopting a cross-sectional study design on 616 geriatric subjects selected by multistage sampling procedure from urban Varanasi, India. Pre-designed, pre-tested proforma and appropriate tools and standard techniques were used for assessing socioeconomic deprivation, food insecurity, nutritional status, morbidities, functional and psychological status of subjects. In order to find out inter-linkages, all significant variables in univariate $\left(\chi^{2}\right)$ analysis were subjected to logistic regression model. In logistic regression analysis higher odds of severe (AOR 14.98; 95\% CI 5.62-39.96) and moderate (7.89; 95\%CI 4.19-14.86) food insecurity at household level prevailed in subjects with SED. Besides Chronic Energy Deficiency (CED) (2.18; 95\% CI 1.32-3.60), moderate/severe depression (5.06; 95\% CI $2.02-12.66)$ has been linked with household food insecurity. Higher odds for moderate and severe $(2.45$; 95\% CI 1.13-5.34) and mild (1.75; 95\% CI 1.08-2.82) depression were identified in CED victims. There existed a significant linkage between presence of morbidity and assisted as well as severe physical dependency. Higher adjusted odds (2.37; 95\% CI 1.54-3.65) for depression prevailed in subjects with physical dependency. Policy shift from socio economic upliftment to food security and sensitivities of families and community for geriatric care in illness and physical dependency are required for wellbeing of geriatric subjects.
\end{abstract}

Keywords: Depression, food insecurity, morbidities, nutritional status, socio economic deprivation.

\section{INTRODUCTION}

Globally, most significant social change of improved standard of living is population ageing. The consequences of contributing factors like significant decline in fertility rate, increase in life expectancy, advancement in medical treatment and technology, prevention and eradication of many infectious diseases and improved nutrition, hygiene and sanitation have enhanced the growth rate of older population worldwide. The proportion of the world's elderly population in 2000 was $11 \%$ and it is estimated that it will be almost doubled (i.e. $20 \%$ ) by 2050 . In case of developing countries, $9 \%$ of the population is aged 60 years or above and this proportion will be more than doubled (i.e. $19 \%$ ) by 2050 , reaching $27 \%$ by 2100 (United Nations, 2012; 2013). India is also not far from this process; it is the second largest country in the world in terms of geriatric population (Swarnalatha, 2013). The rising trend in proportion of aged 60 years and above exists in India; it was 7.4\% in 2001; 8.6\% in 2011 and it is expected to rise upto $10.7 \%$ by 2021 (India, Registrar General and Census Commissioner of India, 2011).

India is going through rapid economic and socio cultural transitions. Although these transitions are considered as significant indicators of progress, they have brought many challenges to the geriatric subjects as well. These rapid changes may force geriatric subjects to experience loss of social roles, loss of self esteem, limit their economic resources and depleted social networks.

"Corresponding author ("priya.bhu2010@gmail.com; (iD https://orcid.org/0000-0001-8952-5660) 
Being of old age, acomplicated period of life, one has to deal not only with the physical aging, but also with the challenges affecting their mental and social wellbeing. The problems faced by geriatric subjects are often complex than adults; and differ according to sociocultural, economic and health of individuals. These complicated life changes in old age substantially give rise to negative emotions such as hopelessness, anxiety, loneliness, which in turn lead to social withdrawal and apathy and further contribute to a more serious outcome in form of depression.

Besides various physiological changes; geriatric subjects are vulnerable to Socio Economic Deprivation (SED), food and nutrition insecurity, poor nutritional status, morbidities, physical dependence, mental and psychological problems like cognitive impairment and depression; these have significant influence on their overall wellbeing and may lead them to a disadvantaged position. Paucity of explicit information about interlinkages of these issues among geriatric subjects may further jeopardise their condition due to lack of focused policies and programmes related to geriatric health.

In the context of sustainable development goals addressing socio economic deprivation, food and nutrition insecurity, under nutrition, morbidities, physical dependence, cognitive impairment and depression are of paramount importance for human health (United Nations, 2018). In old age, socio economic deprivation tends to be more permanent than other age groups and the subjects from this group are unlikely to come out of the poverty trap (Hurd, 1990). Their peace and prosperity are at stake due to their vulnerability to physical and mental health as well as high social dependence. Several authors reported that geriatric subjects faces a higher incidence of poverty (" $U$ " shaped of relationship of age and poverty) in comparison to other age groups (Barrientos et al., 2003; Mujahid et al., 2008). Geriatric subjects in general and very old subjects in particular are vulnerable to disease onset (Joshi et al., 2003; Prakash et al., 2004) and disease increase the risk of poor nutritional status (Hickson, 2006). Poor nutritional status (malnutrition) are common in poor socio economic status (Pryer \& Rogers, 2006). According to Cabrera et al. (2007), Clark et al. (2007) and Manju \& Krishnababu (2013), poor nutritional status (malnutrition) of geriatric subjects are associated with several neuropsychological problems such as depressive symptoms, as well as impaired cognitive function, which are very common in old age. Apart from poor and/or limited financial status as strong associate of depression in old age, functional impairment, cognitive impairment, co/morbidities and chronic illness are also considered as potential risk factors of depressive state of geriatric subjects (Anand, 2014; Goyal \& Kajal, 2014; Manju \& Krishnababu, 2013; Sanjay, 2014; Sengupta \& Benjamin, 2015).

In spite the available evidence of interlinked problems in geriatric subjects, the comprehensive inter-linkages of the problems in old age have been a least explored area of research. Therefore, it is worthwhile to assess interlinkages of above mentioned problems in old age. With this background, the present study was conducted among urban geriatric subjects with the objective of examining inter-linkages among socio-economic deprivation, food insecurity, nutritional status, self-reported morbidities, physical dependency, as well as cognitive impairment and depression in urban geriatric subjects.

\section{METHODOLOGY}

\section{Study design and setting}

This community based cross sectional study was conducted in urban Varanasi, India. Total population of Varanasi district is $3,682,194$, of which urban population was 1,599,260 (43.4\%). Average literacy rate of Varanasi district was $77.05 \%$. The geriatric population covers $7 \%$ of the total population of the district. This district administers 1,535 square kilometers of areas with density of 2,395 people per square meter (India, Registrar General and Census Commissioner of India, 2011).

\section{Subjects and sample size}

Urban geriatric subjects of age 60 years and above were selected for this study. Through literature search Socio Economic Deprivation (SED) was found as the main cause of major issues (viz., food insecurity, poor nutritional status, self-reported morbidities and physical dependency as well as cognitive impairment and depression) occurred in urban geriatric subjects (Jung et al., 2001; Pandey, 2009; Anand, 2014; Sengupta \& Benjamin, 2015). Therefore, it was taken as the basis for estimation of the sample size. Taking a prevalence of $40 \%$ for SED (Pandey, 2009), 5\% permissible error (absolute), design effect of 1.5 and non response rate allowance $(10 \%$ of estimated sample size), the final sample size worked out to be 616 . Of 616 selected subjects complete information was obtained from 604 subjects in the first visit. In 12 subjects information could not be obtained due to their non availability at the time of first visit. In order to get complete information from all (616) subjects additional visits (1-2) were made for these remaining 12 subjects. 


\section{Data collection and sampling technique}

This study was approved by the Institute Ethical Committee of Banaras Hindu University, India. Geriatric subjects consenting for the study were included in the study, whereas subjects with any terminal illness or having serious mental abnormality and also if their duration of stay in the study area was less than six months, he/she were excluded from the study. Only those subjects satisfying inclusion and exclusion criteria were considered for selection as study subjects. All 616 subjects were selected for this study through multistage sampling procedures with following steps: [i] Out of 90 census enumeration wards in the Varanasi city, 9 wards were selected by simple random sampling; [ii] In the selected census enumeration wards households were selected according to probability proportion to size adopting systematic random sampling method; [iii] In the selected households one family was selected randomly using lottery method and [iv] In the selected family one study subject was selected randomly using lottery method. Before interviewing the subjects, written consent was taken from them using informed bilingual (Hindi \& English) consent form and necessary support and counseling was extended to them.

\section{Tools and techniques}

The primary tool used to obtain information of the study subjects was predesigned and pretested proforma. Through this proforma subjects were specifically interviewed about SED, food insecurity status, selfreported morbidities, physical dependency, cognitive impairment and depression. Socio Economic Deprivation was assessed through interview of the head of the family or any responsible member of the family. Subjects with SED were assessed based on the norms of Below Poverty Line (BPL) criteria proposed by Rangarajan Committee, Government of India (2014). Subjects with per capita income less than Rs. 1410/- per month were considered having SED (Rangarajan Committee, 2014). Household Food Insecurity Access Scale developed by Food and Nutrition Technical Assistant (FANTA III) project was used to access household food insecurity. This scale explored anxiety and uncertainty about the household food supply, insufficient quality of food and insufficient food intake through 9 questions. Subject/ any responsible family member was interviewed using this scale and based on their response the scores were calculated and households were categorised in to four categories (viz., food secure, mildly food insecure, moderately food insecure and severely food insecure) (Coates et al., 2007). Anthropometric measurements (viz., weight and height) were done to assess nutritional status of the subjects. Recording of weight through Libra weighing scale (100 gm) and height by Steel anthropometric rod with parallel bars $(0.01 \mathrm{~cm})$ were done following standard techniques (Jelliffe, 1966). Body Mass Index (BMI) of each subject was calculated using formula $\mathrm{BMI}=$ weight $(\mathrm{kg}) /$ height $(\mathrm{m})^{2}$ and their nutritional status was categorised as Chronic Energy Deficiency $\left(<18.5 \mathrm{~kg} / \mathrm{m}^{2}\right)$, Normal $\left(18.5-22.99 \mathrm{~kg} / \mathrm{m}^{2}\right)$, Over weight $\left(23-24.99 \mathrm{~kg} / \mathrm{m}^{2}\right)$ and Obese $\left(\geq 25 \mathrm{~kg} / \mathrm{m}^{2}\right)$, based on World Health Organisation (2000) criteria for Asian population.

Morbidities reported by subjects were assessed by interviewing them; whereas information about physical dependency of subjects was assessed through Barthel's Index of Activity of Daily Living (ADL) (Mahoney \& Barthel, 1965). This scale was used to measure the physical dependency of the geriatric subject's performance in ten activities of daily life (i.e., feeding, grooming, bathing, dressing, bowel and bladder care, toilet use, mobility, transfer, and stair climbing), which served as the basis for categorisation of physical dependency as no physical dependency (no ADL involvement), assisted physical dependency (assisted ADL performance) and severe physical dependency (restriction of any ADL with maximum severity) (Keshari \& Shankar, 2017). In order to find out cognitive impairment, Mini-Mental State Examination (MMSE) was used (Cullen et al., 2007). For assessment of depression status of subjects, Geriatric Depression Scale (GDS) was administrated on them (Kakrani et al., 2015). Different scales (viz, Household Food Insecurity Access Scale, Barthel's Index of Activity of Daily Living, Mini-Mental State Examination and Geriatric Depression Scale) were used in this study to elicit information were pretested in non-study area and necessary changes were done.

\section{Statistical analysis}

Data thus obtained were entered in a personal computer; cross tables and figures were generated by using Statistical Package (SPSS) version 22.0 IBM Corp., Armonk, NY. For inferential purpose Pearson's Chi square test and logistic regression analysis (Adjusted Odds Ratio and 95\% Confidence Interval) were applied. Association among SED, food insecurity, nutritional status, self-reported morbidities, physical dependency, cognitive impairment and depression were established through Pearson's Chi square test. Variables having $\mathrm{p}$ value $<0.05$ were considered as statistically significant and were put in the logistic regression model. In the logistic regression analysis, all significant variables were stepwise put to pin-point the inter-linkages among them. To identify the inter-linkages of SED with household 
food insecurity, nutritional status, cognitive impairment and depression were used as dependent variables. In case of household food insecurity, SED, nutritional status, cognitive impairment and depression status were used as dependent variables, whereas for nutritional status, SED, household food insecurity, self-reported morbidities, physical dependency and depression status were taken as dependent variables. For self-reported morbidities, nutritional status, physical dependency, cognitive impairment and depression status were taken as dependent variables. Adjusted Odds Ratio (AOR) for physical dependency was assessed by putting nutritional status; self-reported morbidities and depression status as dependent variables. In case of cognitive impairment, except nutritional status all other variables were used as dependent variables. For depression status, all variables were taken as dependent variables.

\section{RESULTS}

\section{Characteristics of study subjects}

This study was conducted on 616 geriatric subjects. Of those subjects, $63.6 \%$ belonged to age group $60-69$ years. Gender wise $54.7 \%$ subjects were female; $14.8 \%$

Table1: Association of socio-economic deprivation with food insecurity, nutritional status, self-reported morbidities and physical dependency as well as cognitive impairment and depression.

\begin{tabular}{|c|c|c|c|c|c|c|c|}
\hline \multirow[t]{2}{*}{ Particulars } & \multicolumn{2}{|c|}{$\begin{array}{l}\text { With SED } \\
(\mathrm{N}=234)\end{array}$} & \multicolumn{2}{|c|}{$\begin{array}{l}\text { Without SED } \\
\qquad(\mathrm{N}=382)\end{array}$} & \multicolumn{2}{|c|}{$\begin{array}{r}\text { Total } \\
(\mathrm{N}=616)\end{array}$} & \multirow[t]{2}{*}{ Test of significance } \\
\hline & No & $(\%)$ & No & $(\%)$ & No & $(\%)$ & \\
\hline \multicolumn{8}{|l|}{ Household Food insecurity } \\
\hline Food secure & 9 & 3.8 & 187 & 49.0 & 196 & 31.8 & $\chi^{2}: 3148.2$ \\
\hline Mild & 32 & 13.7 & 147 & 38.5 & 179 & 29.1 & \multirow{2}{*}{ df:3 } \\
\hline Moderate & 102 & 43.6 & 40 & 10.5 & 142 & 23.1 & \\
\hline Severe & 91 & 38.9 & 8 & 2.0 & 99 & 16.1 & $\mathrm{p}:<0.01$ \\
\hline \multicolumn{8}{|l|}{ Nutritional Status } \\
\hline CED & 138 & 59.2 & 136 & 35.9 & 274 & 44.8 & \multirow[t]{2}{*}{$\chi^{2}: 38.90$} \\
\hline Normal & 78 & 33.5 & 161 & 42.5 & 239 & 39.1 & \\
\hline \multirow[t]{2}{*}{ Over weight/Obese } & 17 & 7.3 & 82 & 21.6 & 99 & 16.2 & df: 2 \\
\hline & & & & & & & $\mathrm{p}:<0.01$ \\
\hline \multicolumn{8}{|l|}{ Self-reported physical morbidities } \\
\hline Nil & 74 & 31.6 & 135 & 35.3 & 209 & 33.9 & \multirow[t]{2}{*}{$\chi^{2}: 1.87$} \\
\hline $1-2$ & 96 & 41.0 & 136 & 35.6 & 232 & 37.7 & \\
\hline \multirow[t]{2}{*}{$\geq 3$} & 64 & 27.4 & 111 & 29.1 & 175 & 28.4 & df: 2 \\
\hline & & & & & & & $\mathrm{p}:>0.05$ \\
\hline \multicolumn{8}{|c|}{ Physical dependency on the basis of ADL involvement } \\
\hline _No Physical dependency & 100 & 42.7 & 186 & 48.7 & 286 & 46.4 & $\chi^{2}: 3.58$ \\
\hline Assisted Physical dependency & 105 & 44.9 & 142 & 37.2 & 247 & 40.1 & \multirow{2}{*}{ df:2 } \\
\hline \multirow[t]{2}{*}{ Severe Physical dependency } & 29 & 12.4 & 54 & 14.1 & 83 & 13.5 & \\
\hline & & & & & & & $\mathrm{p}:>0.05$ \\
\hline \multicolumn{8}{|l|}{ Cognitive impairment } \\
\hline Without cognitive impairment & 170 & 72.6 & 308 & 80.6 & 478 & 77.6 & $\chi^{2}: 5.31$ \\
\hline With cognitive impairment & 64 & 27.4 & 74 & 19.4 & 138 & 22.4 & $\begin{array}{r}\text { df: } 1 \\
\mathrm{p}:<0.05\end{array}$ \\
\hline \multicolumn{8}{|l|}{ Depression status } \\
\hline Normal & 133 & 56.8 & 300 & 78.5 & 433 & 70.3 & $\chi^{2}: 38.98$ \\
\hline Mild depression & 59 & 25.2 & 62 & 16.2 & 121 & 19.6 & \multirow{2}{*}{ df:2 } \\
\hline \multirow[t]{2}{*}{ Moderate/Severe depression } & 42 & 17.9 & 20 & 5.2 & 62 & 10.1 & \\
\hline & & & & & & & $\mathrm{p}:<0.01$ \\
\hline
\end{tabular}


and $20.6 \%$ subjects were widower and widowed, respectively. Majority (82.6\%) of them were Hindu whereas, $51.6 \%$ belonged to Other Backward Caste (OBC). As much as $35.2 \%, 29.6 \%$ and $35.2 \%$ subjects were from nuclear, joint and three generation families, respectively. In all $16.5 \%$ subjects were self-employed, whereas $17.9 \%$ were unemployed. Nearly 4 out of 10 subjects $(40.9 \%)$ were illiterate. As much as $41.9 \%$ subjects belonged to upper lower plus lower class.

The results of interlinkages among variables are presented in the following sections:

\section{[A] Linkages of socio-economic deprivation}

There is a significant $(p<0.05)$ association of SED with food insecurity at household level, nutritional status, cognitive impairment and depression status of the study subjects (Table 1). As much as 3.8\% subjects with SED and $49.0 \%$ subjects without SED were from food secure houses; in the respective categories mild food insecurity at household level prevailed in $13.7 \%$ and $38.5 \%$ subjects. Out of 234 subjects with SED, $82.5 \%$ had food insecurity at household level as moderate/severe. Chronic Energy Deficiency and overweight/obesity were present in $59.2 \%$ and $7.3 \%$ in subjects with SED, respectively. As much as $72.6 \%$ subjects with SED and $80.6 \%$ subjects without SED were without cognitive impairment. Mild and moderate/severe depression was present in $25.2 \%$ and $17.9 \%$ subjects with SED, respectively.

Logistic regression for SED (Table 2) revealed that in comparison to subjects having food security at household level as food secure + mild food insecure, AOR for SED was significantly more for subjects with household food security as severe food insecure (AOR 14.98; 95\% CI 5.62-39.96) and moderate food insecure (AOR 7.89; 95\%CI 4.19-14.86). For nutritional status, cognitive impairment, moderate/severe depression and mild depression, AOR for SED were 1.48 (95\% CI: 0.812.72), 1.19 (95\% CI: $0.52-2.63), 1.55$ (95\% CI: $0.54-$ $4.41)$ and 1.41 (95\% CI: 0.68-2.94), respectively.

\section{[B] Linkages of food insecurity at household level}

Associations of household food insecurity with nutritional status, self-reported morbidities and physical dependence as well as psychosocial status are given in Table 3. Prevalence of nutritional status, in geriatric subjects increased considerably with increasing levels of food insecurity. Nutritional status was least $(28.9 \%)$ in subjects whose household food security was categorised as food secure; whereas, this was maximum $(80.6 \%)$ in subjects having household food security as severe food

Table 2: Logistic regression analysis for linkages of socio-economic deprivation

\begin{tabular}{|c|c|c|c|c|c|c|}
\hline \multirow[t]{2}{*}{ Particulars } & \multirow[t]{2}{*}{ Estimate of $\beta$} & \multirow[t]{2}{*}{ SE of $\beta$} & \multirow[t]{2}{*}{ P value } & \multirow[t]{2}{*}{ AOR } & \multicolumn{2}{|c|}{$95 \% \mathrm{CI}$} \\
\hline & & & & & Lower & Upper \\
\hline \multicolumn{7}{|l|}{ Household insecurity } \\
\hline Severe food insecurity & 2.71 & 0.50 & 0.000 & 14.98 & 5.62 & 39.96 \\
\hline Moderate food insecurity & 2.07 & 0.32 & 0.000 & 7.89 & 4.19 & 14.87 \\
\hline Food secure+ Mild food insecurity (Reference) & ---- & ---- & ---- & ---- & ---- & ---- \\
\hline \multicolumn{7}{|l|}{ Nutritional status } \\
\hline $\mathrm{CED}+$ overweight/obese & 0.39 & 0.31 & 0.203 & 1.48 & 0.81 & 2.72 \\
\hline Normal (Reference) & ---- & ---- & ---- & ---- & ---- & ---- \\
\hline \multicolumn{7}{|l|}{ Cognitive impairment } \\
\hline With Cognitive impairment & 0.18 & 0.40 & 0.652 & 1.19 & 0.52 & 2.63 \\
\hline Without Cognitive impairment (Reference) & ---- & ---- & ---- & ---- & ---- & ---- \\
\hline \multicolumn{7}{|l|}{ Depression status } \\
\hline Moderate/severe depression & 0.44 & 0.54 & 0.416 & 1.55 & 0.54 & 4.41 \\
\hline Mild depression & 0.35 & 0.37 & 0.354 & 1.41 & 0.68 & 2.94 \\
\hline Normal (Reference) & ---- & ---- & ---- & ---- & ---- & ---- \\
\hline
\end{tabular}


insecure. Prevalence of overweight/obese was $27.3 \%$, $20.1 \%$ and $7.1 \%$ in subjects having household food security as secure, mild and moderate food insecurity, respectively. None of the study subjects having severe food insecurity at household level had overweight/ obese. There existed significant $(\mathrm{p}<0.01)$ association between nutritional status of study subjects and food security at household level. As much as $85.2 \%$ subjects from food secure houses were without cognitive impairment, whereas from food insecure houses $74.0 \%$ were without cognitive impairment $(\mathrm{p}<0.01)$. As much as $75.4 \%$, $67.6 \%$ and $80.8 \%$ subjects having mild, moderate and severe food insecurity at household level, respectively, were without cognitive impairment. With increasing grade of food insecurity there has been a significant decline in subjects without depression; this is supported by the observation that $82.7 \%, 76.0 \%, 59.9 \%$ and $50.5 \%$ subjects from food secure, mild food insecure, moderate and severe food insecure houses, respectively, were without depression $(\mathrm{p}<0.01)$. There existed no significant $(p>0.05)$ association between household food insecurity and physical dependency of study subjects as well as their self-reported morbidities.

Besides significant linkage between SED and household food insecurity stated earlier (Table 2), logistic regression for household food insecurity further revealed that when normal + overweight/obese subjects were taken as reference; AOR for chronic energy deficiency was 2.18 (95\% CI: 1.32-3.60). In comparison to subjects without depression AOR for household food insecurity in subjects with moderate and severe depression was 5.06 (95\% CI: 2.02-12.66). Taking subjects without cognitive

Table 3: Association of household food insecurity with nutritional status, self-reported morbidities and physical dependency as well as cognitive impairment and depression.

\begin{tabular}{|c|c|c|c|c|c|c|c|c|c|c|c|}
\hline \multirow{3}{*}{ Particulars } & \multicolumn{11}{|c|}{ Food insecurity } \\
\hline & \multicolumn{2}{|c|}{$\begin{array}{l}\text { Food secure } \\
(\mathrm{N}=196)\end{array}$} & \multicolumn{2}{|c|}{$\begin{array}{c}\text { Mild } \\
(\mathrm{N}=179)\end{array}$} & \multicolumn{2}{|c|}{$\begin{array}{l}\text { Moderate } \\
(\mathrm{N}=142)\end{array}$} & \multicolumn{2}{|c|}{$\begin{array}{l}\text { Severe } \\
(\mathrm{N}=99)\end{array}$} & \multicolumn{2}{|c|}{$\begin{array}{c}\text { Total } \\
(\mathrm{N}=616)\end{array}$} & \multirow[t]{2}{*}{$\begin{array}{c}\text { Test of } \\
\text { significance }\end{array}$} \\
\hline & No & $(\%)$ & No & $(\%)$ & No & $(\%)$ & No & $(\%)$ & No & $(\%)$ & \\
\hline \multicolumn{12}{|l|}{ Nutritional status } \\
\hline CED & 56 & 28.9 & 72 & 40.2 & 67 & 47.5 & 79 & 80.4 & 274 & 44.8 & \multirow{3}{*}{$\begin{array}{r}\chi^{2}: 92.09 \\
\text { df: } 6\end{array}$} \\
\hline Normal & 85 & 43.8 & 71 & 39.7 & 64 & 45.4 & 19 & 19.4 & 239 & 39.1 & \\
\hline \multirow[t]{2}{*}{ Overweight } & 53 & 27.3 & 36 & 20.1 & 10 & 7.1 & 0 & .0 & 99 & 16.2 & \\
\hline & & & & & & & & & & & \multirow[t]{2}{*}{$\mathrm{p}:<0.01$} \\
\hline \multicolumn{11}{|l|}{ Self- reported morbidities } & \\
\hline Nil & 59 & 30.1 & 73 & 40.8 & 39 & 27.5 & 38 & 38.4 & 209 & 33.9 & \multirow{3}{*}{$\begin{array}{r}\chi^{2}: 11.29 \\
\text { df: } 6\end{array}$} \\
\hline $1-2$ & 73 & 37.2 & 62 & 34.6 & 57 & 40.1 & 40 & 40.4 & 232 & 37.7 & \\
\hline \multirow[t]{2}{*}{$\geq 3$} & 64 & 32.7 & 44 & 24.6 & 46 & 32.4 & 21 & 21.2 & 175 & 28.4 & \\
\hline & & & & & & & & & & & \multirow[t]{2}{*}{$\mathrm{p}:>0.01$} \\
\hline \multicolumn{11}{|c|}{ Physical dependency on the basis of ADL involvement } & \\
\hline No Physical dependency & 104 & 53.1 & 77 & 43.0 & 62 & 43.7 & 43 & 43.4 & 286 & 46.4 & $\chi^{2}: 5.28$ \\
\hline $\begin{array}{l}\text { Assisted Physical } \\
\text { dependency }\end{array}$ & 69 & 35.2 & 76 & 42.5 & 59 & 41.5 & 43 & 43.4 & 247 & 40.1 & df: 6 \\
\hline $\begin{array}{l}\text { Severe physical } \\
\text { dependency }\end{array}$ & 23 & 11.7 & 26 & 14.5 & 21 & 14.8 & 13 & 13.1 & 83 & 13.5 & $\mathrm{p}:>0.01$ \\
\hline \multicolumn{12}{|l|}{ Cognitive impairment } \\
\hline $\begin{array}{l}\text { Without cognitive } \\
\text { impairment }\end{array}$ & 167 & 85.2 & 135 & 75.4 & 96 & 67.6 & 80 & 80.8 & 478 & 77.6 & \multirow{2}{*}{$\begin{array}{r}\chi^{2}: 15.75 \\
\text { df: } 3 \\
\mathrm{p}:<0.01\end{array}$} \\
\hline $\begin{array}{l}\text { With cognitive } \\
\text { impairment }\end{array}$ & 29 & 14.8 & 44 & 24.6 & 46 & 32.4 & 19 & 19.2 & 138 & 22.4 & \\
\hline \multicolumn{12}{|l|}{ Depression status } \\
\hline Normal & 162 & 82.7 & 136 & 76.0 & 85 & 59.9 & 50 & 50.5 & 433 & 70.3 & $\chi^{2}: 55.77$ \\
\hline Mild & 24 & 12.2 & 37 & 20.7 & 32 & 22.5 & 28 & 28.3 & 121 & 19.6 & \multirow{2}{*}{ df:6 } \\
\hline Moderate/Severe & 10 & 5.1 & 6 & 3.4 & 25 & 17.6 & 21 & 21.2 & 62 & 10.1 & \\
\hline & & & & & & & & & & & $\mathrm{p}:<0.01$ \\
\hline
\end{tabular}


Table 4: Logistic regression analysis for linkages of household food insecurity

\begin{tabular}{|c|c|c|c|c|c|c|}
\hline \multirow[t]{2}{*}{ Particulars } & \multirow[t]{2}{*}{ Estimate of $\beta$} & \multirow[t]{2}{*}{ SE of $\beta$} & \multirow[t]{2}{*}{$\mathrm{P}$ value } & \multirow[t]{2}{*}{ AOR } & \multicolumn{2}{|c|}{$95 \% \mathrm{CI}$} \\
\hline & & & & & Lower & Upper \\
\hline \multicolumn{7}{|l|}{ Nutritional status } \\
\hline Chronic Energy Deficiency & 0.78 & 0.26 & 0.002 & 2.18 & 1.32 & 3.60 \\
\hline $\begin{array}{l}\text { Normal+ Over weight/ Obese } \\
\text { (Reference) }\end{array}$ & --- & -- & --- & --- & --- & --- \\
\hline \multicolumn{7}{|l|}{ Cognitive impairment } \\
\hline With Cognitive impairment & 0.15 & 0.34 & 0.651 & 1.17 & 0.59 & 2.28 \\
\hline $\begin{array}{l}\text { Without Cognitive impairment } \\
\text { (Reference) }\end{array}$ & --- & --- & --- & --- & --- & -- \\
\hline \multicolumn{7}{|l|}{ Depression } \\
\hline Moderate/Severe depression & 1.62 & 0.47 & 0.001 & 5.06 & 2.02 & 12.66 \\
\hline Mild depression & 0.50 & 0.32 & 0.111 & 1.65 & 0.89 & 3.06 \\
\hline $\begin{array}{l}\text { Normal } \\
\text { (Reference) }\end{array}$ & --- & --- & --- & --- & --- & --- \\
\hline
\end{tabular}

Table 5: Logistic regression analysis for linkages of nutritional status

\begin{tabular}{|c|c|c|c|c|c|c|}
\hline \multirow[t]{2}{*}{ Particulars } & \multirow[t]{2}{*}{ Estimate of $\beta$} & \multirow[t]{2}{*}{ SE of $\beta$} & \multirow[t]{2}{*}{ P value } & \multirow[t]{2}{*}{ AOR } & \multicolumn{2}{|c|}{$95 \% \mathrm{CI}$} \\
\hline & & & & & Lower & Upper \\
\hline \multicolumn{7}{|l|}{ Self reported morbidities } \\
\hline $3 \&$ above & 0.02 & 0.27 & 0.947 & 0.98 & 0.58 & 1.66 \\
\hline $1-2$ & 0.13 & 0.23 & 0.569 & 1.14 & 0.72 & 1.79 \\
\hline Nil (Reference) & --- & --- & --- & -- & --- & --- \\
\hline \multicolumn{7}{|c|}{ Physical dependency on the basis of ADL involvement } \\
\hline Severe physical dependency & 0.38 & 0.37 & 0.295 & 0.683 & 0.33 & 1.39 \\
\hline Assisted physical dependency & 0.12 & 0.22 & 0.562 & 0.883 & 0.58 & 1.35 \\
\hline No physical dependency (Reference) & --- & --- & --- & --- & --- & --- \\
\hline \multicolumn{7}{|l|}{ Depression status } \\
\hline Moderate/Severe depression & 0.89 & 0.39 & 0.023 & 2.45 & 1.13 & 5.31 \\
\hline Mild depression & 0.56 & 0.25 & 0.22 & 1.75 & 1.08 & 2.82 \\
\hline Normal (Reference) & --- & --- & --- & --- & --- & --- \\
\hline
\end{tabular}


impairment as reference AOR for household food insecurity was 1.17 (95\% CI: $0.59-3.28)$ for subjects with cognitive impairment (Table 4).

\section{[C] Linkages of nutritional status}

In univariate analysis nutritional status was significantly associated with SED, household food insecurity; selfreported morbidities and physical dependency on the basis of ADL involvement, as well as cognitive impairment and depression status. As much as $42.3 \%, 31.0 \%$ and $26.8 \%$ subjects, characterised as normal on the basis of their BMI, had nil, 1-2 and $\geq 3$ self-reported morbidities ( $p<0.01$ ). Of 239 normal subjects, on the basis of BMI, $49.0 \%$ were without any physical dependency, whereas $38.1 \%$ and $13.0 \%$ subjects had assisted physical dependency and severe physical dependency, respectively. Of 99 overweight/obese subjects, 55.6\%, $39.4 \%$ and $5.1 \%$ subjects had no physical dependency, assisted physical dependency and severe physical dependency, respectively $(\mathrm{p}<0.05)$. Out of 274 subjects with chronic energy deficiency, $58.4 \%, 25.5 \%$ and $16.1 \%$ were characterised as normal, with mild and moderate/ severe depression, respectively; corresponding values for normal subjects were $76.2 \%, 18.0 \%$ and $5.9 \%$. As much as $90.9 \%, 7.1 \%$ and $2.0 \%$ overweight/obese subjects were characterised as normal, with mild and moderate/ severe depression, respectively $(\mathrm{p}<0.01)$. As much as $75.2 \%$ CED, $78.7 \%$ normal and $82.8 \%$ overweight/obese subjects were without any cognitive impairment. There existed no significant $(p>0.05)$ association between nutritional status of subjects and their cognition.

Besides, significant linkage with household food insecurity (section B), logistic regression for nutritional status further identified significant linkage with depression status of study subjects (Table 5); AOR for moderate and severe depression was 2.45 (95\% CI: 1.13-5.34), whereas for mild depression this was 1.75 (95\% CI: $1.08-2.82)$. There existed no significant linkage between nutritional status and morbidity as well as physical dependence identified on the basis of performance of ADL.

\section{[D] Linkages of self-reported morbidities}

There existed a significant $(\mathrm{p}<0.01)$ association between self-reported morbidities and physical dependency. As much as $70.8 \%, 38.8 \%$ and $27.4 \%$ subjects with nil, $1-2$ and $\geq 3$ self-reported morbidities were with no physical dependency, whereas $1.9 \%, 15.5 \%$ and $24.6 \%$ subjects from respective categories had severe physical dependency. In case of $12.4 \%$ subjects without selfreported morbidities, there was cognitive impairment, whereas this was $25.0 \%$ and $30.9 \%$ in subjects having $1-2$ and $\geq 3$ self-reported morbidities, respectively. As much as $79.9 \%, 72.4 \%$ and $56.0 \%$ subjects having selfreported morbidities as nil, 1-2 and $\geq 3$, respectively, were categorised as normal on depression status. Out of 175 subjects with $\geq 3$ self-reported morbidities, $26.3 \%$ subjects had mild depression. In contrast to this, $18.2 \%$ without any self-reported morbidity and $15.9 \%$ subjects with 1-2 self-reported morbidity had mild depression. As much as $19 \%, 11.6 \%$ and $17.7 \%$ subjects having selfreported morbidities nil, 1-2 and $\geq 3$, respectively, had moderate/severe depression.

The linkages between presence of morbidity and physical dependency was significant both in univariate and logistic regression analysis. In comparison to no physical dependency, AOR for self-reported morbidities in subjects with severe physical dependency and assisted physical dependency were 2.31 (95\% CI: 1.22-4.39) and 1.97 (95\% CI: 1.28-3.04), respectively (Table 6). As presented earlier, no significant association existed between self-reported morbidity and SED (Section A) and household food insecurity (Section B) in univariate analysis. The significant association between selfreported morbidity and nutritional status got eliminated in logistic regression analysis (Section C).

\section{[E] Linkages of physical dependency}

Cognitive impairment increased significantly $(\mathrm{p}<0.01)$ with involvement of ADL; $16.1 \%$ subjects with no physical dependency, $22.3 \%$ with assisted physical dependency and $44.6 \%$ subjects having severe physical dependency had cognitive impairment. Out of 286 subjects without physical dependency, $84.3 \%, 14.0 \%$ and $1.7 \%$ were categorised as normal, with mild and moderate/severe depression, respectively, whereas in case of 83 subjects having severe physical dependency corresponding values were $38.6 \%, 26.5 \%$ and $34.9 \%$. Mild and moderate/severe depression was present in $23.9 \%$ and $11.3 \%$ subjects having assisted physical dependency, respectively. A significant $(\mathrm{p}<0.01)$ association existed among physical dependence, cognitive impairment and depression status of subjects.

Besides, significant linkage of physical dependency with self-reported morbidities as presented section D revealed that, in the event of physical dependency, AOR for depression was 2.37 (95\% CI: 1.54-3.65). There was no significant linkage between ADL involvement and cognitive impairment (Table 7). 
Table 6: Logistic regression analysis for linkages of self-reported morbidity

\begin{tabular}{|c|c|c|c|c|c|c|}
\hline \multirow[t]{2}{*}{ Particulars } & \multirow[t]{2}{*}{ Estimate of $\beta$} & \multirow[t]{2}{*}{ SE of $\beta$} & \multirow[t]{2}{*}{ P value } & \multirow[t]{2}{*}{ AOR } & \multicolumn{2}{|c|}{$95 \% \mathrm{CI}$} \\
\hline & & & & & Lower & Upper \\
\hline \multicolumn{7}{|c|}{$\begin{array}{l}\text { Physical dependency on the basis of } \\
\text { ADL involvement }\end{array}$} \\
\hline & $0 \rho$ & (0) & (n) & & & 40 \\
\hline Severe physical dependency & 0.84 & 0.33 & 0.010 & 2.31 & 1.22 & 4.39 \\
\hline Assisted physical dependency & 0.68 & 0.22 & 0.002 & 1.97 & 1.28 & 3.04 \\
\hline $\begin{array}{l}\text { No physical dependency } \\
\text { (Reference) }\end{array}$ & --- & --- & --- & --- & --- & --- \\
\hline \multicolumn{7}{|l|}{ Cognitive impairment } \\
\hline With Cognitive impairment & 0.07 & 0.26 & 0.79 & 0.93 & 0.56 & 1.56 \\
\hline $\begin{array}{l}\text { Without Cognitive impairment } \\
\text { (Reference) }\end{array}$ & --- & --- & --- & --- & --- & --- \\
\hline \multicolumn{7}{|l|}{ Depression status } \\
\hline Moderate severe depression & 0.02 & 0.35 & 0.951 & 0.98 & 0.49 & 1.95 \\
\hline Mild depression & 0.29 & 0.24 & 0.237 & 1.34 & 0.83 & 2.16 \\
\hline Normal (Reference) & --- & ---- & --- & ---- & --- & --- \\
\hline
\end{tabular}

Table 7: Logistic regression analysis for linkages of physical dependency

\begin{tabular}{lrrrrrr}
\hline Particulars & Estimate of $\beta$ & SE of $\beta$ & P value & AOR & \multicolumn{2}{c}{$95 \%$ CI } \\
\cline { 5 - 6 } & & & & & Lower & Upper \\
\hline Cognitive impairment & 0.09 & 0.24 & 0.69 & 1.09 & 0.69 & 1.75 \\
With Cognitive impairment & --- & --- & --- & --- & --- & -- \\
Without Cognitive impairment (Reference) & & & & & & \\
& & & & & & \\
Depression status & 0.86 & 0.22 & 0.000 & 2.37 & 1.54 & 3.65 \\
Depressed & --- & --- & --- & --- & -- \\
Normal (Reference) & & & & & - & - \\
\hline
\end{tabular}

\section{[F] Linkage of cognitive impairment}

In comparison to subjects without cognitive impairment mild (17.8\% versus $26.1 \%)$ and moderate/severe $(6.9 \%$ versus $21.0 \%$ ) depression were more present in subjects with cognitive impairment. In respective categories, $75.3 \%$ and $52.9 \%$ did not have depression. A significant $(p<0.01)$ association existed between cognitive impairment and depression status of study subjects. As mentioned in the previous sections (A to E), results of logistic regression analysis revealed that cognitive impairment was not significantly linked with SED, food insecurity, nutritional status, self-reported morbidities and physical dependence. Significant association of cognitive impairment with depression status of subjects got eliminated in the logistic model.

\section{[G] Linkages of depression status of study subjects}

Results presented earlier reveal in summative manner on the basis of logistic regression that there existed significant linkage between depression and household food insecurity (Section B), nutritional status (Section C) and physical dependence (Section E). Other significant parameters in univariate analysis (viz; socio economic deprivation, self-reported morbidity and cognitive impairment) were eliminated in the logistic model.

Summative figure of inter-linkages among socioeconomic deprivation, food insecurity, nutritional status, self-reported morbidities and physical dependence, as well as cognitive impairment and depression are given in Figure 1. 


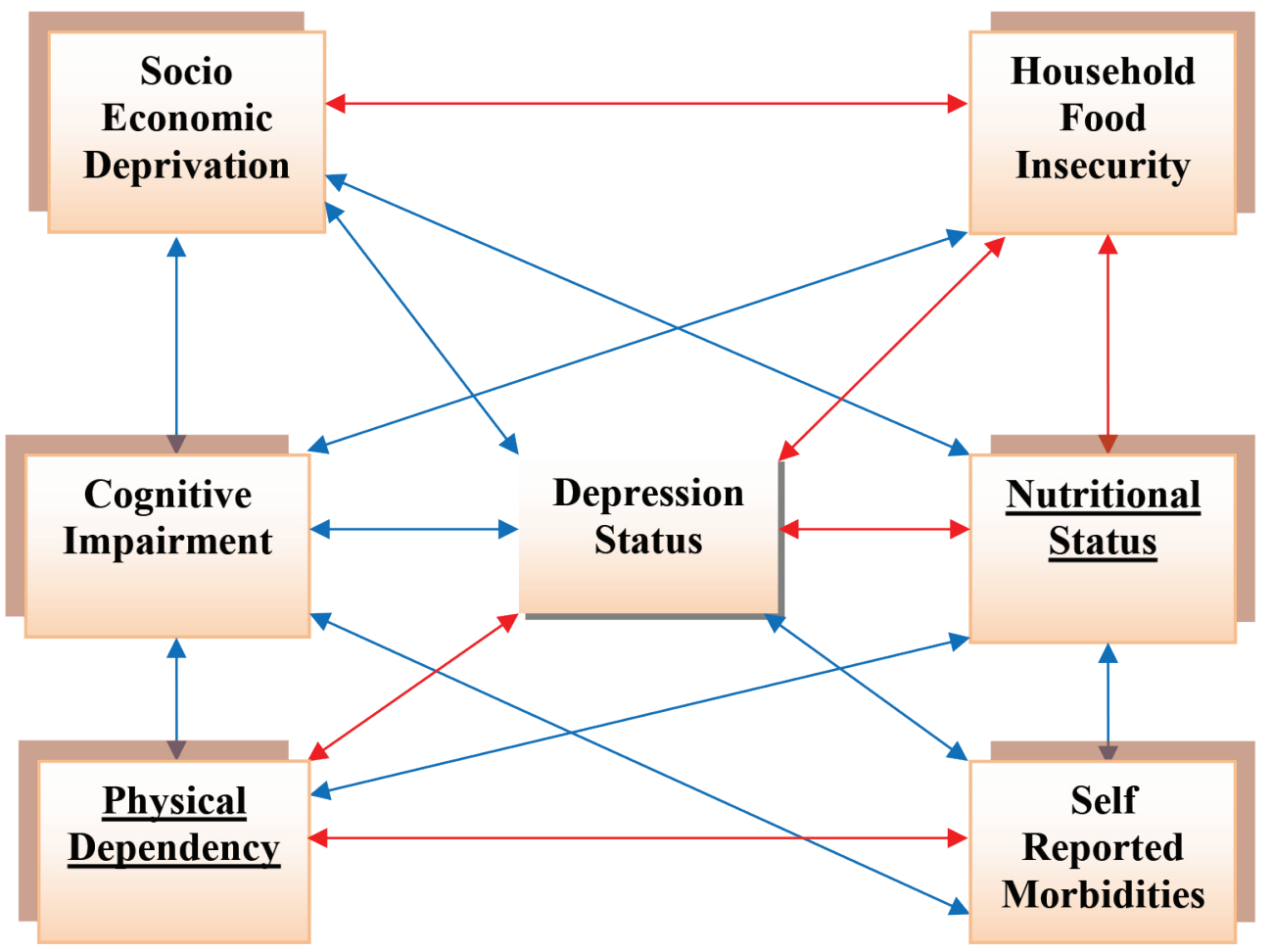

Figure 1: Summative figure of inter-linkages

Note: Significant (cursor): significantly associated in univariate analysis.

Significant (cursor): significantly linked in logistic regression analysis.

\section{DISCUSSION}

In this study, higher odd of moderate/severe food insecurity at household level prevailed in subjects with SED. In India, aging diminishes capacity to participate in the work force (Pandey, 2009). Growing risk of serious illnesses in elderly population increase risk of SED. Being not engaged in income generation activities provides a sense of insecurity, unless there is economic support from the family

Household food insecurity is likely to exert significant influence on nutritional status of its members in general, and geriatric subjects, in particular. Findings of this study are in consonance with this statement. Predictors of experienced household food insecurity are directly or indirectly related to low income/ poverty/socio economic deprivation as supported by study in North India and another study in the United States of America (Agarwal et al., 2009; Lee \& Frongillo, 2001). Household food insecurity is also significantly linked to chronic energy deficiency. This is also supported by findings of research in Turkey (Simsek et al., 2013) and Malaysia (Suzana et al., 2002). The significant linkage between household food insecurity and moderate/severe depression in geriatric subjects of this study could be due to worry and stress caused by not being able to provide enough meals to the members of their family, in terms of quality and quantity. According to a study in United States, household food insecurity may affect ADL performance (Lee \& Frongillo, 2001). This could be attributed to severe under nutrition, decreased immunity and more number of illnesses and their severity.

In conformity with the findings of this study (viz. significant association of CED and functional status of subjects), reports within India (Mathew et al., 2016) and outside India (Brownie, 2006) also provided existence of significant association between nutritional status and ADL involvement. Studies from Turkey (Simsek et al., 2013) and South India (Reddy et al., 2004) also confirmed that self-reported morbidities/health status increased the risk of malnutrition in geriatric subjects. Linkage of CED with depression has been observed in this study. 
A study from South India reported that depression was more among those with poor nutritional status (Manju \& Krishnababu, 2013).

Risk of undernutrition is enhanced by the presence of food insecurity (Brownie, 2006; Simsek et al., 2013). Food insecurity and not having enough money for food expenses are associated with under nutrition in elderly subjects (Suzana et al., 2002). CED has been found to be linked to the presence of number of chronic diseases in elderly and their perception about health status as bad/ very bad. Being orthopedically disabled was found to significantly increase the risk of malnutrition in geriatric subjects (Simsek et al., 2013). Brownie et al. (2006) reported that lack of mobility, chronic diseases, medicine use and hospitalisation were putting elderly at the risk of malnutrition. A study from South India reported that among functional characteristics Instrumental Activity of Daily Living (IADL) dependence was significantly associated with malnutrition (Mathew et al., 2016). In this study logistic regression analysis identified significant linkage between CED and depression in geriatric subjects. Elderly subjects with unintentional weight loss are likely at a higher risk of depression.

In conformity to the finding of present observation, studies conducted in South India (Manju \& Krishnababu, 2013; Sharma et al., 2016; Sanjay et al., 2014), West region of India (Seby et al., 2011), North eastern region of India (Saika \& Mahanta, 2013) have also reported that multiple co-morbid conditions in geriatric subjects were associated with high rate of depression. A study in Southern part of Punjab, North India also reported that chronic illness was associated with depression status of elderly subjects (Goyal \& Kajal, 2014). According to a study in six low middle income countries (viz., China, India, Ghana, Mexico, Russia and South Africa), the presence of multiple morbidity condition was positively associated with depressive symptoms (Anand, 2014). Presence of morbidity (blood pressure) was associated with cognitive impairment, whereas dementia was associated with several chronic diseases (Samuel et al., 2016; Seby et al., 2011).

Some reports from outside India (Brownie, 2006; Simsek et al., 2013) have pinpointed linkage between nutritional status (CED) and self-reported morbidity. This has been supported by a study conducted in South India (Srinivasan et al., 2010). Linkages of physical dependency with self-reported morbidities in geriatric subjects have been also reported in studies in Nigeria (Gureje et al., 2006) and Shimla Hills of North India (Sharma et al., 2013). Physical dependency with selfreported morbidities is understandable. Any illness of serious nature in geriatric subjects is likely to affect physical capacity adversely. In conformity with the finding of this study that physical dependencey is associated with cognitive impairment. Studies from South India (Samuel et al., 2016; Srinivasan et al., 2010) and North India reported that a putative relationship exists between cognitive impairment and functional status (Kumar et al., 2014).

Linkage of physical dependency with depression in geriatric subjects may be attributed to their feeling of helplessness or seeking help for daily activities. According to a study in urban tea garden of India, higher probability of disability prevailed in subjects with BMI $>$ $25 \mathrm{~kg} / \mathrm{m}^{2}$ (Medhi et al., 2006) However, this linkage was not substantiated by the logistic model in this study.

In the present study, significant association of cognitive impairment with SED (Section A), household food insecurity (Section B), self-reported morbidity (Section D), physical dependency (Section E) and depression status got eliminated in logistic model. However, a number of studies have pinpointed linkages of cognitive impairment with nutritional status (Sharma et al., 2013), presences of chronic conditions (Villarreal et al., 2015), ADL involvement (Holz et al., 2013; Villarreal et al., 2015) and depression (Holz et al., 2013).

Linkage between depression and ADL involvement has also been reported in a study conducted in Panama (Villarreal et al., 2015). Linkage of depression with chronic illness in elderly subjects has been identified in studies conducted in China (Cong et al., 2015), Ethiopia (Grima et al., 2016) and Panama (Villarreal et al., 2015) in logistic model. However, this was not substantiated in the present study on the basis of logistic model. A study among elderly people of Peoples Republic of China found cognitive impairment to be associated with increased risk of depression in adjusted model (Giri et al., 2016). However, logistic regression analysis has not substantiated this linkage in the present study.

In a classical model, socioeconomic deprivation predisposes to food insecurity. This has been substantiated by the findings of the present study as well. There is evidence that direct linkage exist between household food insecurity and SED. Surprisingly, no significant linkage has been observed between SED and CED in the logistic model. Several anti poverty and employment generation programmes were instituted in India to remove poverty (Mishra, 2012). However, they could not reduce under nutrition to the desired extent. Several programmes with impressive infrastructure having intention to improve nutrition have been planned in the 
country but due to lack of coherent monitoring/tracking systems and absence of intersectoral corporation they were not properly implemented and their translational effect was not noticed adequately (Keshari \& Shankar, 2016).

Summative figure of this study emphasises that socioeconomic upliftment per se may not improve nutritional status of geriatric subjects. Other underlining processes are responsible for household food security which is linked to CED in logistic model in this study. Elderly people are vulnerable to disease onset (Joshi et al., 2003; Prakash et al., 2004) which leads to CED (Hickson et al., 2006). CED in elderly is linked to depression (Cabrera et al., 2007) as well as impaired cognitive function (Clark et al., 2007). Although cause and effect relationship cannot be established precisely by this cross sectional study, findings of this study provide significant inputs for planning and execution of geriatric services.

Issues prevailing to household food security are critical for geriatric health. Therefore, this should be taken into account by all stakeholders in programme planning and its execution. Community members need to be sensitive about problems of elderly so that a great commitment and involvement in extending support to them be assured to address the issues of health care, functional disability and psychosocial problems. There is a need to strengthen geriatric care services in the existing public health system so that the increasing physical and mental health care demands of elderly can be met.

\section{CONCLUSION}

This study primarily explored interlinkages among socioeconomic deprivation, food insecurity, nutritional status, self-reported morbidities, physical dependency as well as cognitive impairment and depression in urban geriatric subjects. Although this comprehensive study has been conducted on an adequate and representative sample size, and captured the nutritional, social, mental as well as psychosocial issues pertaining to old age and pinpointed interlinkages among them, being cross sectional in nature, it poses a limitation, as cause and effect relationship cannot be established precisely. For establishment of cause and effect relationship a longitudinal study is required. Despite this limitation, the current study provides an interplay of issues affecting physical, mental and social dimensions of health of geriatric subjects. This study further emphasises that ensuring household food security, rather than socioeconomic upliftment, improves nutritional status of geriatric subjects and call for critical scrutiny for underlying mechanism. Nutritional status of geriatric subjects exerts significant influence on extent of depression, which in turn has direct linkage with physical dependency consequent to multiple morbidities. Based on the findings of the current research work, it can be recommended that there should be a policy shift from socioeconomic upliftment to food and nutrition security through multisectoral involvement and participation of stakeholders. A geriatric-sensitive environment needs to be created to cope with morbidities, functional incapacities and psychosocial problems in geriatric subjects. Focused interventional programmes should be designed and implemented, giving due consideration to interlinkages of issues having direct bearing on health and functional capacity of geriatric subjects.

\section{REFERENCES}

Agarwal, S., Sethi, V., Gupta, P., Jha, M., Agnihotri, A. \& Nord, M. (2009) Experimental household food insecurity in an urban underserved slum of North India, Food Security, 1(3), pp: 239-50.

DOI: https://doi.org/10.1007/s12571-009-0034-y

Anand, A. (2014) Understanding depression among older adults in six low middle income countries using WHO-SAGE survey, Behavioral health, 1(2), pp: 1-11.

Berrintos, A., Gorman, M. \& Heslop, A. (2003) Old age poverty in developing countries: contributions and dependence in later life, World Development, 31(3), pp: 555-570.

DOI: https://doi.org/10.1016/S0305-750X(02)00211-5

Brownie, S. (2006) Why are elderly individuals at risk of nutritional deficiency?, International Journal of Nursing Practice, 12(2), pp: 110-118.

DOI: https://doi.org/10.1111/j.1440-172X.2006.00557.x

Cabrera, M. A. S., Mesas, A. E., Garcia, A. R. L. \& Andrade, S. M. (2007) Malnutrition and depression among communitydwelling elderly people, Journal of the American Medical Directors Association, 8(9), pp: 582-584.

DOI: https://doi.org/10.1016/j.jamda.2007.07.008

Clark, R., Birks, J., Nexo, E., Ueland, P. M., Schneede, J., Scott, J., Molloy, A., \& Evans, J. G. (2007) Low vitamin B-12 and risk of cognitive decline in older adults, The American Journal of Clinical Nutrition, 86(5), pp: 1384-1391.

DOI: https://doi.org/10.1093/ajen/86.5.1384

Coates, J., Swindale, A. \& Bilinsky, P. (2007) Household Food Insecurity Access Scale (HFIAS) for measurement of food access: indicator guide, Version 3-Washigton, DC: Food and Nutrition Technical Assistance (FANTA) Project, pp: 1-29 [Online] Available from: www.fao.org/fileadmin/user-upload/ eufao-fsi4dm/doc-training/hfias.pdf [Accessed: 28 ${ }^{\text {th }}$ May 2013].

Cong, L., Dou, P., Chen, D. \& Cai, L. (2015) Depression and associated factors in the elderly Cadres in Fuzhou China: A 
community based study, International Journal of Gerontology, 9(1), pp: 29-33.

DOI: https://doi.org/10.1016/j.ijge.2015.02.001

Cullen, B., Neil, O. B., Evans, J. J., Coen, E. R. F., Lawlor, B. A. (2007) A review of Screening tests for cognitive impairment, Journal of Neurology, Neurosurgery \& Psychiatry, 78(8), pp: 790-799.

DOI: https://doi.org/10.1136/jnnp.2006.095414

Giri, M., Chen, T., Yu, W. \& Lu, Y. (2016) Prevalence and correlates of cognitive impairment and depression among elderly people in the world's fastest growing city, Chongqing, People's Republic of China, Clinical Interventions in Aging, 11, pp: 1091-1098.

DOI: https://doi.org/10.2147/CIA.S113668

Goyal, A. \& Kajal, K. (2014) Prevalence of depression in elderly population in the Southern part of Punjab, Journal of Family Medicine Prim Care, 3(4), pp: 359-361.

DOI: https://doi.org/10.4103/2249-4863.148109

Grima, M., Hailu, M., Wakwoya, A., Yohannis, Z. \& Ebrahim, J. (2016) Geriatric depression in Ethiopia: Prevalence and associated factors, Journal of Psychiatry, 20 (1), pp: 1-5.

DOI: https://doi.org/10.4172/2378-5756.1000400

Gureje, O., Ogunniyi, A., Kola, L. \& Afolabi, E. (2006) Functional disability among elderly Nigerians: results from the Ibadan study of ageing, Journal of the American Geriatrics Society, 54(11), pp: 1784-1789.

DOI: https://doi.org/10.1111/j.1532-5415.2006.00944.x

Hicksom, M. (2006) Malnutrition and Ageing, Postgraduate Medical Journal, 82(963), pp: 2-8.

DOI: https://doi.org/10.1136/pgmj.2005.037564

Holz, A. W., Nunes, B. P., Thume, E., Lange, C. \& Facchini, L. A. (2013) Prevalence of cognitive impairment and associated factors among the elderly in Bage, Rio Grande do Sul, Brazil, Revista Brasileira de Epidemiologia, 16(4), pp: 880-888.

DOI: https://doi.org/10.1590/S1415-790X2013000400008

Hurd, M. D. (1990) Research on the elderly: Economic Status, retirement and consumption and saving, Journal of Economic Literature, 28(2), pp: 565-637.

India, Registrar General \& Census Commissioner of India (2011) Census of India, New Delhi: Ministry of Home Affairs [Online] Available from: https://censusindia.gov.in/2011common/census_2011.html [Accessed: 29 ${ }^{\text {th }}$ March 2017].

Jelliffe, D. B. \& World Health Organization (1966) The assessment of the nutritional status of the community (with special reference to field surveys in developing regions of the world), Geneva: World Health Organization.

Joshi, K., Kumar, R. \& Avasthi, A. (2003) Morbidity profile and its relationship with disability and psychological distress among elderly people in Northern India, International Journal of Epidemiology, 32(6), pp: 978-987.

DOI: https://doi.org/10.1093/ije/dyg204

Jung, S. L., Edward, A. \& Frongillo J. R. (2001) Factors associated with food insecurity among US elderly persons importance of functional impairments, The journal of Gerontology: Social Sciences, 56(2), pp: S94-S99.

DOI: https://doi.org/10.1093/geronb/56.2.S94

Kakrani, V. A., Desale, A. V. \& Mehta, C. P. (2015) Geriatric depression scale (GDS): A tool for assessment of depression in elderly, Journal of Krishna Institute of Medical Sciences University, 4(3), pp: 24-31.

Keshari, P. \& Shankar, H. (2017) Prevalence and spectrum of functional disability of urban elderly subjects: A community based study from central India, Journal of Family \& Community Medicine, 24(2), pp: 86-90.

Keshari, P. \& Shankar, H. (2016) Strategic gaps in provision of universal nutrition security: Indian Perspective, International Journal of Food and Nutritional Sciences, 5(1), pp: 54-65.

Kumar, S., Tiwari, S. C., Tripathi, R. K. \& Pandey, N. M. (2014) Socio economic status has bearing on the Mini Mental State Examination Score among Indian urban elderly, Journal of Geriatric Mental Health, 1(2), pp: 90-93.

DOI: https://doi.org/10.4103/2348-9995.152428

Lee, J. S. \& Frongillo Jr, E. A. (2001) Factors associated with food insecurity among US elderly persons: importance of functional impairments, The Journals of Gerontology Series B: Psychological Sciences and Social Sciences, 56(2), pp: 94-99.

DOI: https://doi.org/10.1093/geronb/56.2.S94

Mahoney, F. I. \& Barthel, D. W. (1965) Functional evaluation: The Barthel Index, Maryland State Medical Journal, 14, pp: 61-65.

DOI: https://doi.org/10.1037/t02366-000

Manju, S. \& Krishnababu, G. (2013) Epidemiological Study of depression among population above 60 years in Vishakhapatanam, India, International Journal of Medical Sciences and Public Health, 2(3), pp: 695-702.

DOI: https://doi.org/10.5455/ijmsph.2013.030520133

Mathew, A. C., Das, D., Sampath, S., Vijayakumar, M., Ramkrishnan, N. \& Ravishankar, S. L. (2016) Prevalence and correlates of malnutrition among elderly in an urban area in Coimbatore, Indian Journal of Public Health, 6(2), pp: 112117.

DOI: https://doi.org/10.4103/0019-557X.184542

Medhi, G. K., Hazarika, N. C., Borah, P. K. \& Mahanta, J. (2006) Health problems and disability of elderly individuals in two population groups from same geographical location, JAPI, 54, pp: 539-544. 
Mishra, C. P. (2012) Nexus of Poverty, Energy Balance and Health, Indian journal of community medicine: official publication of Indian Association of Preventive \& Social Medicine, 37(2), pp: 71-78.

DOI: https://doi.org/10.4103/0970-0218.96083

Mujahid, G., Pannirselvam, J. \& Doge, B. (2008) The Impact of Social Pensions: Perceptions of Asian Older Persons, Bangkok, Thailand: UNFPA Country Technical Services Team for East and South East Asia, pp: 1-59.

Pandey, M. K. (2009) Poverty and disability among Indian Elderly: Evidence from Household Survey, ASARC Working Paper 2009/09, pp: 1-19.

Prakash, R., Choudhary, S. K. \& Singh U. (2004) A study of Morbidity Pattern among geriatric population in an urban area of Udaipur Rajasthan, Indian Journal of Community Medicine, XXIX(1), pp: 35-40.

Pryer, J. \& Rogers, S. (2006) Epidemiology of undernutrition in adults in Dhaka slum households, Bangladesh, European Journal of Clinical Nutrition, 60(7), pp: 815-822.

DOI: https://doi.org/10.1038/sj.ejcn.1602385

Rangarajan Committee (2014) Report on Poverty, New Delhi: Press Information Bureau Government of India Planning Commission, pp: 1-4 [Online] Available from: http://pib.nic. in/newsite/PrintRelease.aspx?relid=108291 [Accessed: $19^{\text {th }}$ May 2017].

Reddy, K. K. R., Reddy, B. K. \& Rao, A. P. (2004) Interaction among body composition, self- rated health and functional status of the elderly in an Indian population, Asia Pacific Journal of Clinical Nutrition, 13(1), pp: 78-75.

Saika, A. M. \& Mahanta, N. (2013) A Study of nutritional status of elderly in terms of Body Mass Index in urban slums of Guwahati City, Journal of the Indian Academy of Geriatrics, 9, pp: 11-14.

Samuel, R., McLachlan, C. S.. Mahadev, U. \& Isaac, V. (2016) Cognitive impairment and reduced quality of life among oldage groups in southern Urban India: home based community residents, free and paid old age homes residents, QJM: An International Journal of Medicine, 109(10), pp: 653-659.

DOI: https://doi.org/10.1093/qjmed/hcw040

Sanjay, T. V., Jahnavi, R., Gangaboraiah, B., Lakshmi, P. \& Jayanthi, S. (2014) Prevalence and factors influencing depression among elderly living in the urban poor locality of Bengaluru city, International Journal of Health and Allied Sciences, 3(2), pp: 105-109.

DOI: https://doi.org/10.4103/2278-344X.132695

Seby, K., Chaudhary, S. \& Chakraborty, R. (2011) Prevalence of psychiatric and physical morbidity in an urban geriatric population, Indian Journal of Psychiatry, 53(2), pp: 121-127. DOI: https://doi.org/10.4103/0019-5545.82535
Sengupta, P. \& Benjamin, A. I.(2015) Prevalence of depression and associated risk factors among the elderly in urban and rural field practice areas of a tertiary care institution in Ludhiana, Indian Journal of Public Health, 59(1), pp: 3-7.

DOI: https://doi.org/10.4103/0019-557X.152845

Sharma, D., Mazta, S. R. \& Parashar, A. (2013) Morbidity pattern and health behavior of aged population residing in Shimla Hills of North India. : A cross sectional study, Journal of Family Medicine and Primary Care, 2(2), pp: 188-193.

DOI: https://doi.org/10.4103/2249-4863.117421

Sharma, K. D., Kadeangadi, D. M. \& Mallapur, M. D. M. (2016) Community based cross sectional study to determine depression among elderly persons residing in urban area of North Karnataka, International Journal of Medical Sciences and Public Health, 5(11), pp: 1-5.

DOI: https://doi.org/10.5455/ijmsph.2016.11042016470

Simsek, H., Maseri, R., Sahin, S. \& Ucku, R. (2013) Prevalence of malnutrition, factors related to malnutrition in the elderly: A community-based, cross-sectional study from Turkey, European Geriatric Medicine, 4(4), pp: 226-230.

DOI: https://doi.org/10.1016/j.eurger.2013.06.001

Srinivasan, K., Vaz, M. \& Thomas, T. (2010) Prevalence of health related disability among community dwelling urban elderly from middle socioeconomic strata in Bangaluru, India, Indian Journal of Medical Research, 131(4), pp: 515-521.

Suzana, S., Earland, J., Suriah, A. R. \& Warnes, A. M. (2002) Social and health factors influencing poor nutritional status among rural elderly Malays, The Journal of Nutrition, Health \& Aging, 6(6), pp: 363-369.

Swarnalatha, N. (2013) Prevalence and determinants of disabilities in rural elderly in Chittoor district Andhra Pradesh, International Journal of Current Research and Review, 5(8), pp: 79-83.

United Nations, Department of Economic and Social Affairs Population Division (2013) World Population Ageing 2013, New York: United Nations.

United Nations Population Division (2012) Population and Ageing and Development 2012, pp. 1-39 [Online] Available from: http://www.un.or/en/development/deas/population/ publications/pdf/ageing/2012PopAgeingandDev_WallChart. pdf [Accessed: 02 ${ }^{\text {nd }}$ May 2016].

United Nations (2018) United Nations Sustainable Development Goals Report 2018, pp: 1-40 [Online] Available from: https:// unstats.un.org/sdgs/files/report/2018/TheSustainableDevelop mentGoalsReport2018-EN.pdf [Accessed: $04^{\text {th }}$ February 2020].

Villarreal, A. E., Grajales, S., Lopez, L., Britton, G. B. \& Panama Ageing Research Initiative (2015) Cognitive impairment depression and co occurrence of both among the elderly in Panama: Differential Associations with Multi-morbidity and 
functional limitations, BioMed Research International, 2015, pp: $1-7$.

DOI: https://doi.org/10.1155/2015/718701
World Health Organization, Regional Office for the Western Pacific (2000) The Asia-Pacific perspective: redefining obesity and its treatment, pp: 378-420, Sydney: Health Communications Australia. 